SANTOS, Maurici Tadeu Ferreira dos; GOMES, Mara Helena de Andréa; SILVEIRA, Cássio. Introdução a uma cartografia sociológica: a Revista de Saúde Pública, 1967 a 1977. História, Ciências, Saúde - Manguinhos, Rio de Janeiro, v.23, n.2, abr.-jun. 2016, p.411-430.

\section{Introdução a uma} cartografia sociológica: a Revista de Saúde Pública, 1967 a $1977^{*}$

\section{Introduction to a social cartography: the journal Revista de Saúde Pública, 1967 to 1977}

\section{Maurici Tadeu Ferreira dos Santos}

Doutor em Saúde Coletiva.

Estrada dos Pires, s.n.

Caixa postal 46

37690-000 - Sapucaí Mirim - MG - Brasil

mauricitadeu@gmail.com

\section{Mara Helena de Andréa Gomes}

Professora, Departamento de Medicina Preventiva/Unifesp-EPM. Rua Pedro de Toledo, $740,4^{\circ}$ andar 04039-002 - São Paulo - SP - Brasil

maraandrea@unifesp.br

\section{Cássio Silveira}

Professor, Departamento de Medicina Social/Faculdade de Ciências Médicas/Santa Casa de São Paulo.

Rua Cesário Mota Junior, 61, $5^{\circ}$ andar 01221-020 - São Paulo - SP - Brasil

cassio.silveira@fcmsantacasasp.edu.br

Recebido para publicação em outubro de 2013.

Aprovado para publicação em maio de 2014.
Resumo

Analisa as dez primeiras edições da Revista de Saúde Pública, publicada pela Universidade de São Paulo, com suporte em metodologia sociocartográfica fundamentada na sociologia do conhecimento de Karl Mannheim. Mapeia artigos e editoriais com vistas à compreensão das transformações no período apresentado. $\mathrm{O}$ processo foi marcado por tensões no âmbito do perfil editorial entre o atendimento aos princípios da instituição e as transformações internacionais, requerendo aberturas para temáticas interdisciplinares. Destaca a movimentação das subáreas mostrando predominância de uma epidemiologia em transição pela absorção de novos saberes no contexto de formação do campo da saúde coletiva.

Palavras-chave: Revista de Saúde Pública; cartografia; periódico científico; sociologia do conhecimento; saúde coletiva.

Abstract

Through reliance on a social cartography method based on Karl Mannheim's sociology of knowledge, the article analyzes the first ten issues of Revista de Saúde Pública, published by the University of São Paulo. Articles and editorials are mapped in order to understand the period's transformations. In the realm of the journal's editorial line, tensions are noted between complying with the principles of the institution and international transformations, which demanded an openness to interdisciplinary topics. Special focus is placed on sub-fields, dominated by an epidemiology that was in flux as it absorbed new knowledge in the context of the formation of the field of public health.

Keywords: Revista de Saúde Pública; cartography; science journal; sociology of knowledge; public health. 
$\mathrm{A}$ produção científica brasileira em saúde pública tomou impulso e ganhou escopo após o aparecimento da Revista de Saúde Pública (RSP), editada pela Faculdade de Saúde Pública da Universidade de São Paulo (FSPUSP) a partir de 1967, ano do lançamento de seu primeiro número, continuidade editorial do Boletim do Instituto de Higiene de São Paulo e dos Arquivos da Faculdade de Higiene e Saúde Pública da USP, de 1919 e 1947, respectivamente. Barros (ago. 2006, p.46) mostra que "entre os 140 periódicos brasileiros indexados, Cadernos de Saúde Pública (CSP), Ciência e Saúde Coletiva, Revista de Saúde Pública e Revista Latino-americana de Enfermagem ocupam do segundo ao quinto lugares em termos de fator de impacto - FI (de dois anos) - para 2005, com valores entre 0,59 e 0,47". Entre 2009 e 2010 a RSP duplicou a média aritmética desse índice, alcançando o valor de 1,11 e, em 2012, apresentou o mais alto FI das revistas nacionais dedicadas à saúde pública/coletiva. Atualmente, os 254 fascículos da RSP apresentam mais de 3.300 artigos publicados desde seu início. Segundo Carvalho et al. (2007), RSP e CSP "lideram as estatísticas das revistas mais consultadas na base Scielo".

Ao longo de mais de 40 anos de existência, a RSP consolidou-se como o veículo no qual os pesquisadores mais publicam no campo da saúde pública/saúde coletiva, particularmente bolsistas de produtividade do Conselho Nacional de Desenvolvimento Científico e Tecnológico vinculado ao Ministério da Ciência e Tecnologia do Brasil (Carvalho et al., 2007, p.3023). Sua expressiva visibilidade a torna almejada para escoamento da produção dos programas de pós-graduação em saúde coletiva no país (Barros, ago. 2006, p.46).

Por esses motivos e como critério de inclusão, apresentamos neste artigo uma metodologia sociocartográfica que permite acompanhar a produção da área na década inaugural, analisando as dez primeiras edições da RSP, compreendendo os anos de 1967 a 1977.

\section{Cartografia sociológica: importação de um conceito e um convite metodológico}

O processo de elaboração cartográfica torna possível descrever relações que se estabelecem num determinado espaço (Catrib, Oliveira, 2010, p.401). Em nosso caso, o "espaço" escolhido foi a produção acadêmica e científica veiculada pela RSP desde o início das publicações até o final da primeira década de edição, local compreendido como de trânsitos e fronteiras.

No entanto, é preciso um esclarecimento. Tomada em sua essência geográfica, a cartografia se traduz na arte de conceber, de levantar, de redigir e divulgar mapas (Joly, 1990). Por intermédio da linguagem cartográfica, essa abordagem metodológica torna possível estudar situações e estabelecer relações. Assim, cartografar é, também, um método de pesquisa e possivelmente de intervenção (Catrib, Oliveira, 2010, p.401).

Para Guimarães e Ribeiro (2010, p.578), o método cartográfico tanto é "resultado do processo de representação das estruturas elementares da realidade quanto ferramenta do processo cognitivo de generalização". Na mesma linha, Brunet (2001) afirma que os modelos gráficos e conceituais não são meras abstrações, e sim resultados de procedimentos racionais de apreensão de relações existentes entre elementos do mundo sensível.

Entendemos que, além de se prestar à ilustração e à facilidade comunicativa, figuras, representações e conceitos cartográficos devem também fornecer suporte para apreciação e avaliação do componente espacial e temporal dos temas em análise. Ao cartografar, exercemos 
o papel ativo de dar-lhes tratamento a partir da avaliação e interpretação dos objetos em perspectiva. Portanto, cartografar é prospectar e habitar um "território" de conhecimento.

Dessa forma, uma cartografia temática permite a realização de um mapa conceitual dos temas escolhidos para publicação; da frequência e relação entre descritores; do surgimento de inflexões temáticas; da conservação e inauguração de termos, ideias e pensamentos contidos nos enfoques editoriais; das ênfases em determinados aspectos conjunturais (às vezes em detrimento de outros, mais estruturais); da descoberta e apreciação de temas singulares e em séries; da distribuição de autores e de suas instituições; e das referências bibliográficas usadas nos artigos, entre outros aportes.

Para essas finalidades, nossa metodologia incluiu uma carta de fichamento dos fascículos e outra conceitual, conforme exemplificadas nos Quadros 1 e 2, respectivamente. A primeira foi elaborada em forma de uma planilha no formato Excel@ , contendo os seguintes dados de cada fascículo: ano, volume, número, autor, instituição, unitermo ou descritor e classificação da subárea. Já a carta conceitual foi concebida a partir do registro das impressões e observações dos itens analisados, de maneira a facilitar a visualização de como os temas evoluem na trajetória espaçotemporal. Em cada uma delas foram registrados termos considerados de destaque nas publicações. Para darmos alguma linearidade, à guisa de exemplo dessa forma de organização, consideramos no Quadro 2 o tema nutrição, que, iniciado em 1967, posteriormente, desdobrou-se em saúde materno-infantil, recebeu aportes da estatística e matemática para, em seguida, expor problemas da desnutrição no país incluindo taxas de mortalidade e - posteriormente - possibilitou cálculos de risco.

Quadro 1: Exemplo de uma carta de fichamento

\begin{tabular}{|l|l|l|l|l|l|l|l|}
\hline Ano & V. & N. & Tipo & Autor & Instituição & Descritor & Subárea \\
\hline 1967 & 1 & 1 & artigo & Mascarenhas, R. & FHSPUSP & Não disponível & Política e gestão \\
\hline 1968 & 2 & 1 & editorial & Forattini, O. & FSPUSP & Não disponível & Pesquisa básica \\
\hline 1971 & 5 & 1 & atualização & Candeias, N. & FSPUSP & Sociologia & Ciências sociais \\
\hline 1972 & 6 & 1 & artigo & Ciari Jr., C. & FSPUSP & Risco gravídico & Epidemiologia \\
\hline 1972 & 6 & 2 & notas & Certain, D. et al. & FSPUSP & Infecção tuberculosa & Epidemiologia \\
\hline
\end{tabular}

Fonte: Elaborado pelos autores.

Quadro 2: Exemplo de carta conceitual mostrando um movimento temático

Linha do tempo

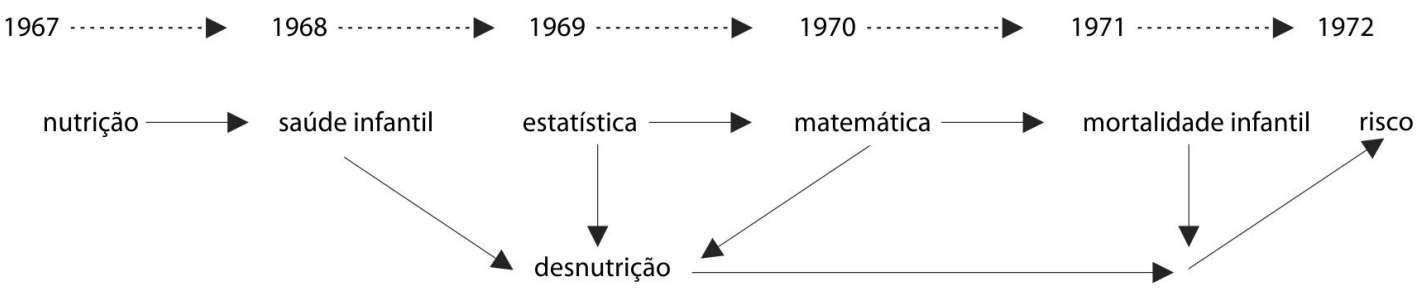

Fonte: Elaborado pelos autores. 


\section{Cartografia sociológica: criação de um itinerário}

Nessa nossa iniciativa, a RSP constituiu a plataforma espacial e temporal de investigação; uma maneira de detectar relações ativas nas fronteiras entre os discursos que validam e dão legitimidade aos processos de divulgação de materiais que se propugnam científicos. Esses constituíram os parâmetros de nossa apropriação dos conceitos e níveis cartográficos, tomando-os de empréstimo do campo da geografia como concepção fértil a uma sociologia do conhecimento da revista.

Para a elaboração de um plano de organização dos níveis de leitura cartográfica com a finalidade de promover a observação, relações e interpretação dos dados, tomamos emprestado o modelo elaborado por Guimarães e Ribeiro (2010) a partir de Libaut (1975), que contém as noções com as quais idealizamos e condensamos nosso mapeamento, conforme disposto no Quadro 3.

Quadro 3: Níveis de leitura cartográfica

\begin{tabular}{|l|l|l|l|}
\hline Nível & Designação & Objetivos & Perguntas \\
\hline 1 & Elementar & Identifica, localiza & O quê? Onde? \\
\hline 2 & De correlação & Relaciona os elementos & Com quem/com qual? Por quê? \\
\hline 3 & De síntese & Classifica (tipologia), julga & Como? Para quê? \\
\hline
\end{tabular}

Fonte: Elaborado pelos autores a partir de Libaut (1975) e Guimarães e Ribeiro (2010).

Quanto ao propósito do tratamento cartográfico da informação, tomamos por referência a definição de Guimarães e Ribeiro (2010, p.580):

Em um nível elementar, a preocupação central do 'mapeador' é apenas a de localização. Quando a preocupação envolve a correlação dos dados, o mapeamento é considerado de segundo nível ou de análise espacial. Por fim, se a representação cartográfica possibilita a construção de tipologias e o tratamento gráfico é um suporte para o julgamento e avaliação do pesquisador, obtém-se um nível mais elevado de leitura: a síntese.

Aqui, o nível "elementar" é entendido como o agrupamento e fichamento do material empírico, elaborado a partir da catalogação geral do periódico ao longo de sua série disponível na base Scielo de 1967 a 1977 e registrado em uma planilha geral (ou carta de fichamento) conforme mostrado no Quadro 1. Registramos os números, os títulos, os autores, instituições, as subáreas e as palavras-chave do periódico, de modo a servir como um "mapa informativo" representante de um primeiro plano de aproximação ao conjunto da obra.

Para a classificação das subáreas utilizamos o critério de Carvalho et al. (2007), que se baseia em descritores para categorização no interior de três pilares proeminentes e constitutivos da saúde pública e coletiva: a epidemiologia, EPI (Quadro 4); as ciências sociais e humanas em saúde, CSHS (Quadro 5) e o planejamento, políticas e gestão em saúde, PPG (Quadro 6). Dessa forma, os artigos foram categorizados em uma ou outra subárea de acordo com a apresentação de unitermos - ou descritores - similares aos qualificadores definidos. Categorizamos como "caixa cinza" (CC) todos os artigos que não apresentaram descritores similares aos qualificadores disponíveis (Quadro 7). Para os artigos anteriores a 1971 (que ainda não disponibilizavam palavras-chave), realizamos a leitura dos resumos, de onde pudemos extrair um ou dois descritores que melhor representassem o conjunto da obra. 


\section{Quadro 4: Qualificadores da subárea epidemiologia (EPI)}

Demografia; estatística; bioestatística; matemática; estudos descritivos, analíticos, clínicos, caso-controle; estimativa; prevalência; incidência; índices; taxas; coeficientes; informações de morbidade, mortalidade, natalidade, fertilidade, subnotificação, risco; medicina preventiva; prevenção; controle; determinação ou determinantes quantitativos de doença ou saúde; saúde ocupacional, ambiental; vigilância epidemiológica e sanitária.

Fonte: Elaborado pelos autores a partir de Carvalho et al. (2007).

\section{Quadro 5: Qualificadores da subárea ciências sociais e humanas em saúde (CSHS)}

Ciências da conduta; direito sanitário; antropologia; sociologia; sociologia médica; medicina social; ética; história da saúde; epistemologia; filosofia; filosofia do conhecimento; serviço social; educação em saúde; avaliação de comportamento ou conduta; pesquisas qualitativas.

Fonte: Elaborado pelos autores a partir de Carvalho et al. (2007).

Quadro 6: Qualificadores da subárea planejamento, políticas e gestão em saúde (PPG)

Administração em saúde; prestação de cuidados em saúde; gestão; recursos humanos; políticas para centros de saúde; unidades sanitárias; planejamento da rede hospitalar; política e administração pública de serviço à comunidade; planificação de assistência médica e ambulatorial; diretrizes de planejamento governamentais; normas/orientações de planejamento; economia da saúde; economia médica; práticas e serviços; público/privado; modelos de atenção à saúde; reforma orçamentária e tributária do setor saúde e educação; planejamento escolar; programas de ensino.

Fonte: Elaborado pelos autores a partir de Carvalho et al. (2007).

\section{Quadro 7: Qualificadores da "caixa cinza" (CC)}

Experimentos com animais; estudos biológicos básicos; microbiologia, zoologia, parasitologia, entomologia, taxonomia, fisiologia animal; nutrição; odontologia; enfermagem; desastres e outras que não se encaixaram nos qualificadores das subáreas.

Fonte: Elaborado pelos autores a partir de Carvalho et al. (2007).

É interessante destacar que nos primeiros anos de publicação alguns temas não apresentavam qualificadores que os correlacionassem imediatamente com a epidemiologia, segundo o critério de Carvalho et al. (2007), como é o caso da nutrição, odontologia e enfermagem que, em seus movimentos investigativos, foram estabelecendo contato mais denso com o raciocínio epidemiológico, passando, portanto, a incluir descritores mais afinados com a subárea.

Entendemos o segundo nível de leitura cartográfica - "correlação" - como as relações tornadas possíveis frente à frequência dos temas, bem como à proximidade ou ao distanciamento entre eles, insinuando singularidades ou séries no decorrer das publicações. As relações também foram possíveis a partir da observação de como se sucediam as designações mais ou menos enfáticas - ou de maiores ou menores predominâncias -, além dos destaques relacionados ao tema central da pesquisa e da migração de conceitos disciplinares, como a tornar possíveis constatações relacionais no panorama do movimento temático.

Por fim, consideramos o nível "síntese" (terceiro nível de leitura cartográfica) aquele que avalia, de maneira geral, a disposição do conteúdo estudado, capaz de servir como suporte para julgamento e avaliação do material segundo o contexto da época estudada, propiciando certas aproximações na identificação de um perfil ou de um padrão editorial.

Na perspectiva da sociologia do conhecimento, reconhecer os dados da história intelectual conduz à "descoberta dos estilos e métodos de pensamento dominantes em determinados tipos de situação histórico-sociais" (Mannheim, 1968, p.27). De antemão, convém reconhecer 
armadilhas de um fetichismo científico. Na busca de objetividade, muitas vezes sacrificamos significados para chegar a formulações mais facilmente definíveis. Entretanto, sabemos que correlações não são recapturadas por aperfeiçoamento de formalização ou por descoberta de funções, motivo pelo qual, juntamente com Mannheim, temos reservas em acreditar "que tal purificação metódica substituísse a riqueza original da experiência" (p.46).

\section{Revista de Saúde Pública: uma releitura das suas origens}

A RSP sempre esteve ligada à Faculdade de Saúde Pública da Universidade de São Paulo (USP), que por sua vez é originária do Laboratório de Higiene (então subordinado à cadeira de higiene da Faculdade de Medicina de São Paulo) criado em 1918 pelo convênio firmado entre o governo do estado de São Paulo e a Fundação Rockefeller. É conveniente destacar alguns acontecimentos desse período, particularmente aqueles que antecederam e sucederam a Primeira Guerra Mundial, já que compõem cenários históricos no contexto da criação do Laboratório de Higiene.

A partir de 1823 os EUA reforçaram suas ações de controle estratégico no continente americano ao efetivar as bases de um movimento que viria a ser conhecido como panamericanismo, expresso ideologicamente pela doutrina Monroe. Um dos primeiros desdobramentos dessa estratégia foi a Conferência da Cidade do México em 1901, com a estruturação da Repartição Sanitária Internacional e a posterior consolidação do relatório de "polícia sanitária", que definiu, segundo Cueto (2007, p.58), os moldes da institucionalização da saúde no continente e pode ser considerado o embrião da Organização Pan-americana de Saúde (Opas/Paho).

Em 1914, a política educacional norte-americana decidiu pela formação das faculdades de higiene e saúde pública, tendo a Junta Internacional de Saúde da Fundação David Rockefeller a responsabilidade de formular normas e critérios para a formação de recursos humanos em saúde nas instituições dos EUA e no exterior (Mello, 2010, p.88). A Fundação Rockefeller estava associada à Fundação Carnegie, uma das responsáveis pelo relatório Flexner, base da implementação e controle no campo de ações médicas-sanitárias, não só no Brasil como em mais de sessenta países ao longo dos anos 1920 (Mello, 2010, p.41). Mello (p.39) registra a presença e influência da Fundação Rockefeller na saúde pública brasileira como "avassaladora", uma vez que,

já na década de 1930, acompanhando a migração da dependência político-financeira brasileira da Europa para os EUA, pouco se podia identificar da antiga influência francesa no discurso setorial para além das gerações educadas antes do advento John Hopkins e memórias de Oswaldo Cruz [sic]. Uma radical mudança epistemológica da medicina urbana para a higiene individual; de uma era bacteriana para a educação sanitária; de uma ciência ainda impregnada de mitos miasmáticos, para a racionalidade e pragmatismo norte-americano.

Em 1920, o Laboratório de Higiene da USP transformou-se em Instituto de Higiene, e mais tarde se tornou Escola de Higiene e Saúde Pública da USP. Desde então já promovia intercâmbios científicos e, como uma forma de divulgar os conhecimentos, criou o Boletim do Instituto de Higiene (série interrompida em 1945 com a criação da Faculdade de Higiene e 
Saúde Pública, FHSPUSP) estimulando o desenvolvimento de ações de prevenção e controle de doenças e epidemias.

No intuito de focar a produção local, em 1947 o Boletim deu lugar à publicação bianual dos Arquivos da Faculdade de Higiene e Saúde Pública da USP, em cujo editorial Geraldo de Paula Souza traçou os compromissos que seriam revisitados por Raphael de Paula Souza (1967, p.2) na primeira edição de 1967: "não significa quebra de continuidade. Ideais, princípios e finalidades são os mesmos. Tanto a Faculdade como a Revista, com o crescimento, passam por transformações, mantendo-se indestrutivelmente ligadas a seu ponto de origem - o Laboratório de Higiene da Faculdade de Medicina".

Se existe um entendimento de que a saúde pública participou de ideais e movimentos reformistas na época do Instituto de Higiene, devemos observar que esse envolvimento deveu muito de seu teor e conteúdo a Geraldo de Paula Souza, cujos ideais são identificados na reforma da saúde que leva seu nome. A reforma Paula Souza previa, entre outras ações, a instalação de cinco centros de saúde na capital de São Paulo. Sua influência exerceu-se em boa parte da história da RSP, do mesmo modo que o itinerário, os valores transmitidos e os padrões acadêmicos estipulados devem créditos a essa figura emblemática.

Geraldo de Paula Souza foi bolsista da primeira turma de Saúde Pública da Johns Hopkins University, contando com a concessão de uma bolsa de estudos financiada pelo International Health Board, ligado à Fundação Rockefeller.

Mas é prudente entender, com Mannheim (1968, p.31), que a emergência de pensamentos e ideias ocorre em situações histórico-sociais específicas: "quem pensa não são os homens em geral, nem tampouco indivíduos isolados, mas os homens em certos grupos que tenham desenvolvido um estilo de pensamento particular em uma interminável série de respostas a certas situações típicas características de sua posição comum".

Importante notar que, antes do término da bolsa de estudos e do retorno de Geraldo de Paula Souza ao Brasil, a administração e a direção do Instituto de Higiene (precursor do ideário da RSP) estavam a cargo de dois norte-americanos - Samuel Darling e Wilson Smillie. $\mathrm{Na}$ base da reforma sanitária em curso vigorava a concepção dos centros de saúde como modelo de atenção.

Muitos autores relatam a ativa presença da Fundação Rockefeller nesse processo, sobretudo pela doutrinação moral, uma vez que formava pessoal para a implantação de um modelo de práticas baseado na operacionalidade racional, pragmática e instrumental que não teria sido possível sem sua decisiva participação, assim como pelos "quadros administrativos que ajudou a formar" (Gomes, 2006, p.532).

Do ponto de vista sociocartográfico, esse trânsito de conhecimentos e formas de pensamento pode representar a capacidade de transmissão e incorporação de conceitos ou de contraconceitos. Como nos aponta Mannheim (1968, p.38), em cada grupo social existem estratos intelectuais distribuídos em diferentes posições de hierarquia social e cultural capazes de dotar seu meio de uma "interpretação de mundo", com diferentes perspectivas sobre um objeto, cada qual gozando de um controle monopolístico sobre a formação da visão de mundo das sociedades. Esses estratos Mannheim denominou intelligentsia. Estritamente nesse sentido, tais grupos tomam para si certas realidades, e é por via do conjunto de suas perspectivas que categorias de pensamento passam por inflexões e são redirecionadas ou mantidas. Validar 
determinadas técnicas, teorias e conceitos em detrimento de outros (contraconceitos), pode ser exemplo do poder - sempre relativo - da intelligentsia.

O refinamento teórico possibilita inferir a posição cultural e intelectual do grupo em questão. É por meio de abstrações cada vez mais elaboradas que alcançamos o próprio objeto sob investigação, uma vez que "a sociologia do conhecimento se torna mais que uma descrição sociológica de fatos que nos informam como certas visões se originaram de um dado milieu; ela passa a ser igualmente uma crítica, pela redefinição do alcance e limites da perspectiva implícita em determinadas afirmativas" (Mannheim, 1968, p.306).

\section{A Revista de Saúde Pública de 1967 a 1977: cartografia da década inaugural}

Ainda que o primeiro editorial garantisse que a RSP não seria destinada exclusivamente à divulgação dos trabalhos dos integrantes daquela faculdade (conforme princípios declarados nos Arquivos da Faculdade de Higiene e Saúde Pública da USP), sua estrutura ainda "se constituía em uma revista fechada" (Souza, 1967, p.2). De fato, mantido como um eixo que consideramos estruturante, a maioria dos artigos foi publicada por pesquisadores vinculados à FHSPUSP, de maneira mais acentuada nos seus três primeiros anos de vida (de 1967 a 1969).

A RSP nasceu com a missão de ampliar a comunicação institucional da faculdade procurando desvencilhar-se de um "hermetismo" autorreferido, posto que oferecia "maior oportunidade para que nela [fossem] publicados trabalhos outros que não os da casa" (Souza, 1967, p.2). Contudo, autores como Yunes, Candeias, Cotillo e Iaria, todos ligados à FHSPUSP, estavam entre os que mais publicavam no seu início, com quase 90\% de artigos, contando com a marcante presença de Oswaldo Paulo Forattini em praticamente todas as edições.

Somente a partir de 1970 notaremos uma gradual contribuição interinstitucional com a presença do Serviço de Erradicação da Malária e Profilaxia da Doença de Chagas, do Instituto Adolfo Lutz, do Instituto Butantã, da Escola Paulista de Medicina e da Secretaria de Saúde do Estado de São Paulo, por intermédio da Divisão de Controle e Combate a Vetores. Confirmando uma antiga crítica da editoria quanto à rigidez estrutural herdada dos boletins da instituição, talvez tenha sido possível que a política do periódico fosse orientada para reduzir sua penetração em alguns meios (da mesma maneira que ocorreu com os Arquivos), ao privilegiar a publicação em outros núcleos internos e de instituições de interesse próximo. Podemos pensar essa situação como uma herança das normas de conduta do grupo editorial anterior?

Como aponta Mannheim (1968, p.20), todo interesse se reflete no pensamento, incluído aquele seu aspecto a que se dá o nome de ciência. Considerando que os interesses do observador guiam o ângulo de visão ou a perspectiva adotada ou, dito de outro modo, que o pensamento se constrói conforme as expectativas de um grupo social específico, "cada conceito incorpora dados da experiência que interessem ao investigador dominar e abranger" (Mannheim, 1968, p.295). Esse traço característico Mannheim denominou ideologia.

Nos primeiros dez anos de publicação da RSP foram editados 11 volumes, com um total de 417 artigos, distribuídos em peças originais, editoriais, comunicações, notas e informações, resumos, conferências, catálogos, notícias, atualizações e novas técnicas. Algo nos chamou atenção em uma primeira aproximação, pois boa parte dos artigos voltava-se para as 
pesquisas cujas ciências de suporte eram a química e a biologia, com trabalhos nas áreas de microbiologia, zoologia e imunologia, lócus predominante dos trabalhos de Oswaldo Forattini, do Departamento de Epidemiologia da então Faculdade de Higiene e Saúde Pública da USP. Raras foram as edições em que não houvesse a presença de ao menos um artigo do autor, muitos dos quais classificamos como "Caixa cinza" (CC). Ao examinar a distribuição de temas, notamos que as subáreas mais proeminentes foram: EPI, com 31\% do total de artigos; PPG, com 14\%; CSHS, com 5\%. O Gráfico 1 mostra as contribuições percentuais de cada subárea no total de publicações. A epidemiologia destacou-se com os seguintes temas: demografia; estatística; estudos descritivos; informações de morbidade, mortalidade, natalidade e fertilidade; risco; determinantes quantitativos de doença e vigilâncias, epidemiológica e sanitária. O ano de 1968 mostrou maior presença dessa subárea, com 60\% do total publicado, seguido de menor concentração em 1971, com 20\% do total de artigos, sendo que o número médio permaneceu estável e na ordem de $30 \%$.

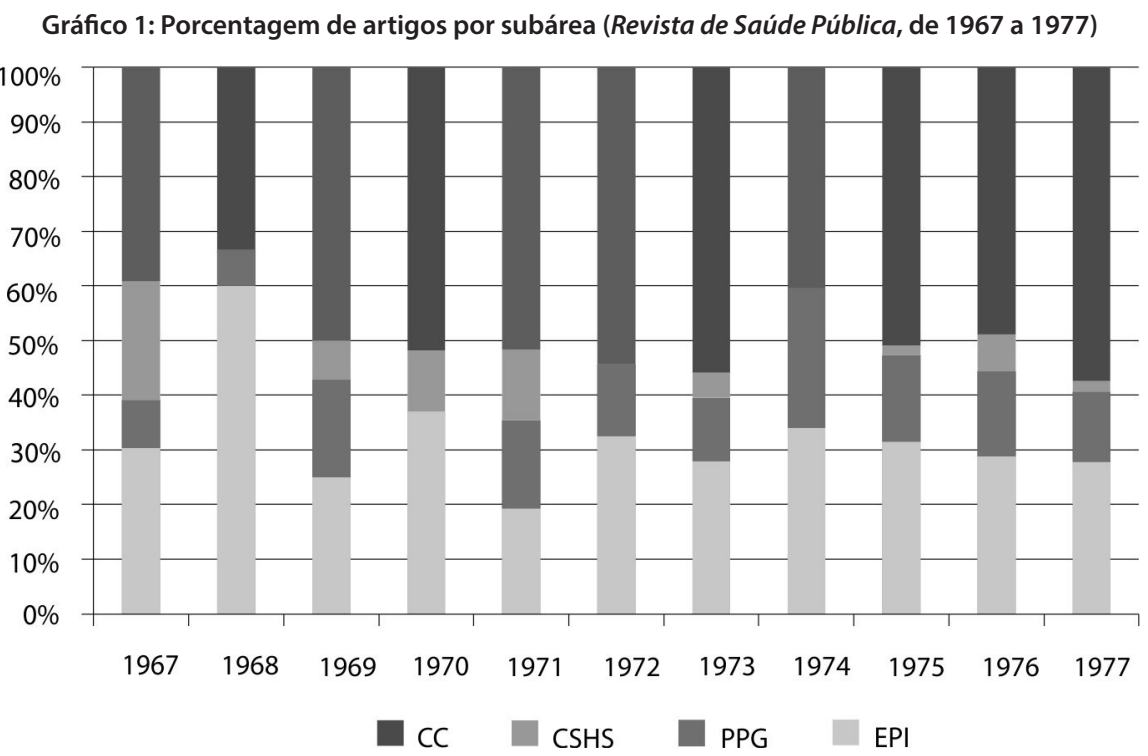

Legenda: CC: Caixa cinza; CSHS: Ciências sociais e humanas em saúde; PPG: Política, planejamento e gestão em saúde; EPI: Epidemiologia

Fonte: Elaborado pelos autores.

Chamou-nos atenção o aumento continuado dos artigos classificados como CC. Indagamos qual teria sido a razão de termos metade de todos os artigos nessa categoria. Recordemos que os qualificadores para a CC foram, predominantemente: experimentos com animais, estudos biológicos básicos, microbiologia, zoologia, parasitologia, entomologia, taxonomia, fisiologia animal e nutrição. Devemos observar, no entanto, que tal critério de inclusão de temas obedeceu a uma classificação mais atualizada (Carvalho et al., 2007) em torno das subáreas predominantes. Se, por um lado, esse procedimento pode suscitar uma incongruência metodológica, por outro expõe a provável existência de eixos epidemiológicos que podem terse modificado no transcorrer do período. Se pensarmos que uma mudança no conhecimento epidemiológico pode influenciar padrões temáticos de classificação, então, no limite, 
também define mais adequadamente seus qualificadores. Apoiados em Mannheim (1968), podemos considerar que disciplinas ou campos de atuação científicos expressam, em última análise, modelos dominantes de pensamento ontologicamente amparados por pressupostos considerados consistentes. Se esses se transformam, então o campo e, por conseguinte, as disciplinas devem acompanhar as novas aquisições. Se considerarmos ainda que a maior frequência de artigos em uma determinada subárea pode identificar o perfil editorial de uma revista, não seria equivocado afirmar que o perfil da RSP seria representado pelos temas da CC. Logo, e apoiados em constatações editoriais, se essa alta frequência estiver associada de alguma maneira aos qualificadores apresentados (muitos deles relacionados com pesquisas entomológicas do Trypanosoma cruzi, Triatoma infestans, Lutzomyia, Biomphalaria tenagophila, Schistosoma mansoni etc.), podemos observar aí um padrão de explicação fortemente baseado na bacteriologia.

Nesse raciocínio, somos levados a crer que uma epidemiologia mais configurada aos qualificadores da CC representou um eixo axiomático a disputar espaço com a configuração da subárea EPI, representada pelos qualificadores de uma epidemiologia "diferente", identificada com diferentes saberes e conhecimentos, até sua mais recente feição ancorada no conceito de risco. É oportuno destacar que os artigos que definimos como CC são matizes de "uma" epidemiologia diferenciada, possivelmente em trânsito, o que pode indicar um movimento entre fronteiras e não apenas uma representante com qualificadores desconexos.

O desempenho apresentado pela subárea da CSHS também mereceu reflexões. Em um dos primeiros artigos editados fora do eixo epidemiológico sensu stricto (referimo-nos à subárea EPI), Armando Piovesan, da disciplina autônoma de ciências sociais aplicadas da FHSPUSP, entendia como acanhada a quantidade de obras publicadas nas áreas de sociologia, antropologia cultural, psicologia da personalidade e psicologia social.

A literatura em ciências da conduta (expressão que além de enfeixar as disciplinas de ciências humanas lhes atribuía o sentido original com que foram incorporadas) presente no periódico era caracteristicamente constituída por vocabulário anglo-saxônico e com reduzida penetração nos campos de medicina, saúde pública, enfermagem e odontologia. De qualquer modo, ao resumir o panorama dessa incorporação, o autor não deixa de destacar que,

assim sendo, predomina ainda, em amplos setores desses domínios científicos, a ignorância a respeito das ciências da conduta e da contribuição que podem oferecer. Outras vezes, o que se encontra é a imagem de que as ciências da conduta não empregam uma metodologia científica; em outras palavras, não seriam realmente ciências. Há, também, os casos em que os trabalhos dos cientistas da conduta não tendo sido coroados de êxito, acabaram por acarretar apreciáveis efeitos negativos, servindo para confirmar a inutilidade dessas ciências (Piovesan, 1967b, p.97-98).

Nesse raciocínio, Mannheim nos é útil novamente para refletir sobre os obstáculos apontados por Piovesan. Entendemos que um deles expressa seu desalento pela ausência de conceito relativo às ciências sociais e humanas. A constatação de um reconhecimento inadequado aos estudos sociais na saúde pode ser pensado em termos da tensão epistemológica entre modos particulares de pensamento. Mannheim (1968, p.296) aponta que "categorias morfológicas de cunho conservador acabam por não romper com a totalidade concreta dos dados de experiência, mas, pelo contrário, preservam-na em toda a sua singularidade". 
Tal premissa é compatível com a constatação de modelos dominantes de pensamento, desde a ontologia pressuposta na pesquisa do problema até o nível de abstração requerido e, finalmente, na ausência - deliberada ou não - de certos conceitos (Mannheim, 1968, p.294). Essa lacuna, por sinal,

frequentemente indica não apenas a ausência de certos pontos de vista, mas também a ausência de um impulso definido para se atingir uma compreensão de certos problemas vitais. Assim, por exemplo, o aparecimento relativamente tardio do conceito de 'social' da história comprova o fato de não se haver até então colocado as questões implicadas no conceito de 'social', e, da mesma forma de não existir, até então, um modo de experiência definido, denotado pelo conceito de 'social' (Mannheim, 1968, p.295).

Note-se que, na década posterior à criação da Campanha Nacional de Aperfeiçoamento de Pessoal de Nível Superior, ${ }^{1}$ Piovesan já destacava um critério de área e subárea que viria a ser incorporado na classificação adotada por esse órgão: a necessidade da criação de um centro latino-americano de ciências sociais aplicadas à saúde. Destacamos também as contribuições de Piovesan em seus primeiros artigos referenciados na então produção norte-americana a respeito da medicina comunitária e da relação público/privado na saúde, como, por exemplo, "Medicina privada e saúde pública estariam convergindo? O problema e argumentos que justificariam o preparo do estudante de medicina em medicina comunitária" (Piovesan, 1967a). Para fundamentar sua ideia de convergência, o autor busca apoio em Bakst (1967), no artigo "Community health and departments of preventive medicine" (Saúde comunitária e os departamentos de medicina preventiva), publicado pelo Archives of Environmental Health dos EUA.

Outros artigos que tiveram alguma relação com as CSHS abordaram a formalização de cursos de educação popular sanitária como prática fundamental de atitudes e comportamentos de higiene - exemplo que pode ser visto em Lucchesi et al. (1969, p.84).

Cabe-nos aqui indagar qual teria sido a corrente teórica que consubstanciava a influência sanitária e higienista transferida/herdada das instituições fomentadoras internacionais. Qual teria sido a razão de não terem sido encontradas referências nos reconhecidos autores europeus, os quais há mais de 150 anos se vinham debruçando sobre questões da saúde das populações, em trabalhos pioneiros abordando problemas demográficos, estatísticos e sociológicos, num movimento de interlocução com as ciências sociais e humanas e - em particular - com a epidemiologia?

Se levarmos em conta o desenvolvimento da epidemiologia europeia, de forte matiz social, exemplos não nos faltam na experiência de James Lind, Gaspar Casal, George Baker, Eduard Jenner, Louis Villermé, John Snow, Ignaz Semmelweis, William Farr e Rudolf Virchow, para citar alguns, cujas obras eram conhecidas desde o final do século XIX e início do século XX.

Nas circunstâncias dos anos 1960, esses autores eram referências para o que se conhecia como medicina urbana, medicina da força de trabalho, polícia médica e, por conseguinte, colaboradores (alguns precursores) da sociologia médica, medicina social e preventiva. Alguns apresentaram a situação de vida de moradores dos núcleos urbanos em fase de expansão industrial e comercial, como documentado no relatório de Villermé em 1828 para a Real Academia Francesa de Medicina; no inquérito governamental realizado pela Sanitary 
Commision da Inglaterra, baseado no relatório de Edwin Chadwick sobre as condições existentes naquele país por volta de 1844, ou ainda no celebrado estudo A situação da classe trabalhadora na Inglaterra, realizado por Friedrich Engels entre 1842 e 1844.

No campo das CSHS, além de autores não menos expoentes e singulares como Max Weber, Georg Simmel e Emile Durkheim, cumpre-nos recuperar nomes a quem a sociologia da saúde e, em particular, a própria epidemiologia devem seus estatutos de reconhecimento. Ressaltamos, por exemplo, que a clássica obra de Durkheim sobre o suicídio não havia sido citada em quaisquer das referências da RSP sobre o tema "mortes por acidentes", em que autores incluíram o suicídio, a exemplo dos artigos de Barbosa (1974) e Silveira e Gotlieb (1976).

Ao que tudo indica, as escolas norte-americanas de higiene tiveram seus fundamentos teórico-científicos provenientes do relatório Flexner e dos conceitos teórico-metodológicos e respectivas instrumentalizações que William Welch havia trazido dos centros laboratoriais europeus. Fazia parte daquele rol de problemas assuntos considerados prioritários, como as cidades, os habitantes e suas migrações, os guetos e seus costumes, a ética, a moral, a delinquência, as estratificações de classe e o choque de culturas.

Em artigo, Ramos (1968) traduz parte da ideologia da formação dos recursos humanos (RH) em saúde (note-se o momento inaugural do termo RH nos artigos) como fator imprescindível ao aperfeiçoamento do sistema de saúde a partir de treinamento e capacitação de profissionais comprometidos com a educação e erradicação da ignorância das condições sanitárias básicas. O tema ressurgiu no artigo de Souza (1976) com referência a Charles-Edward Winslow (1920), pesquisador ligado ao Instituto de Relações Humanas da University of Yale. Um ano depois, o assunto retornou às publicações com Rosa Krauss (1977), com diversas reflexões sobre a formação de recursos humanos para a saúde pública, dessa vez referenciada em George Rosen.

A RSP começa a dar indícios de abertura para a inclusão de outras perspectivas. O tema foi adensado no ano seguinte graças a Alvarenga, Ciari Júnior e Santos (1973), em um trabalho conjunto que apresentava um diálogo possível entre CSHS, EPI e PPG, tendo obras referenciais, até então não citadas nas publicações, de Max Weber, Rodolfo Stavenhagen e Charles Wright Mills. Na mesma edição, Mascarenhas publicou documento sobre a história da saúde pública no estado de São Paulo, e é destacável o primeiro aparecimento do termo "risco" em artigo que atende pelo título "Elementos de avaliação do risco gravídico", que evoca/provoca reflexões sobre a démarche de construção desse paradigma epidemiológico (Ciari Júnior, Almeida, 1972).

O número de artigos aumentava num ritmo expressivo à medida que o periódico ia estendendo sua abrangência no cenário nacional e internacional de pesquisa e ensino. Dos 38 editados entre 1967 e 1968, o número foi elevado para 55 nos dois anos subsequentes, mostrando um aumento apreciável de 50\%. Em seu início (1967), a RSP publicava aproximadamente 23 artigos por edição, terminando com mais de 54 em 1977, em um contínuo crescimento das publicações.

Entram em cena outras instituições, órgãos de outros estados da federação e de outros países, como a Universidade de Pernambuco, a Universidade da Bahia, o Serviço Social da Indústria, o Wellcome Parasitology Unit, além da Associação Paulista de Medicina, para citar alguns. Importante notar que estava em curso a reforma universitária de 1970. Com o aumento do número de vagas nas universidades existentes e mais flexibilidade para abertura de instituições 
de ensino superior privado, uma parcela significativa da classe média ascendente ingressava nas diversificadas modalidades de cursos implantados.

Seguiram-se transformações nas estruturas curriculares de todas as modalidades de ensino superior brasileiro, sendo destacável a introdução de disciplinas das áreas de ciências sociais e humanas (sociologia e/ou antropologia e/ou psicologia) em todas as formações acadêmicas.

Não por acaso, concomitantemente ao nascimento das primeiras turmas de pós-graduação em saúde pública na USP (nos campi Ribeirão Preto e São Paulo), a periodicidade da RSP passa de semestral para trimestral entre 1971 e 1972. O processo de implantação e expansão de programas de pós-graduação em saúde pública ocorreu de forma gradual, sem deixar de expor as desigualdades de acesso: concentrou-se nas regiões Sul e Sudeste do país. Embora ainda não fosse obrigatória a publicação pelos programas recém-implantados, a necessidade de mais veículos de circulação da produção de pesquisas e dos cursos de pós-graduação tornouse premente, assim como sua desconcentração de São Paulo.

A forte censura política do período de 1970 a 1977 em todas as formas impressas de comunicação também se fez sentir nesse plano, talvez pela ausência mesma de textos enviados que pudessem ser censurados (Gomes, Goldenberg, 2003). Temas candentes como as epidemias de encefalite por arbovírus e meningite meningocócica em São Paulo tiveram raros trabalhos registrados como os de Iversson (1976) e os de Arantes e Ruffino-Neto (1977).

Lembremos que as facilidades da informática e internet também não estavam disponíveis na época, muito embora a computação eletrônica, bancos e sistemas de dados por computadores já estivessem presentes desde 1960 em algumas unidades e instituições. Um dos primeiros trabalhos que trataram da informatização de processos, aliando modelagem matemática-estatística aos sistemas de informática e às ciências da computação, apareceu com Silveira (1974), da FSPUSP.

No cenário da saúde pública brasileira, novas demandas políticas e administrativas, associadas a um ideário reformista, começavam a se insinuar no contexto dos debates da área. Estava em gestação um pensamento social que culminaria com as condições particulares dos movimentos transformadores da sociedade brasileira nos anos de 1970 e 1980 . O modelo que se prenunciava criticava, entre outras demandas, o eixo excessivamente econômico da Opas.

O contraponto ao modelo de saúde pública que vinha sendo seguido baseava-se numa proposta inclusiva, que requeria uma melhor e mais adequada percepção sobre a promoção integral e equânime do processo saúde-enfermidade-cuidado. O "novo" modo de pensar a saúde prenunciava dimensões incompatíveis com a constituição e o status quo da política nacional em meados da década de 1970, por não permitir cotejar a saúde de modo integral e nem compartilhar os ganhos sociais no seu âmbito. À medida que aglutinava adeptos, o movimento propunha uma ruptura com a ordem social e política dominante, ao mesmo tempo que explicitava os parâmetros ideológicos em torno dos quais determinados estratos intelectuais e técnicos passariam a conduzir o movimento de reforma do sistema de saúde brasileiro.

De acordo com o que expusemos, aqui podemos observar a formação e ação de uma nova intelligentsia nascente em de seu ideário. Esse movimento não só gerou necessidades de capacitação de recursos humanos na área - agora com um perfil afinado com o ideário que vinha sendo erguido -, como também colaborou na "organização do campo de conhecimento, 
pelas indagações, recortes e posturas teórico-metodológicas oferecidas pelos seus paradigmas" (Canesqui, 1997, p.1).

Assim, abria-se uma perspectiva teórica de produção científica voltada especificamente para o campo em formação, ao mesmo tempo em que se assistia a um esvaziamento do modelo de saúde pública que vigorava até então, baseado em um conceito preventivista (Nunes, 1992). O período em análise também se debate contra um modelo hospitalocêntrico e médicocentrado, como pode ser observado no artigo que trata da função do hospital segundo o sistema brasileiro e a OMS, de autoria de Lima-Gonçalves et al. (1972).

Como seria esperado, críticas e reformulações não ocorreriam sem dificuldades e embates devido às adversidades de integração entre disciplinas, além dos sérios problemas decorrentes da inadequação de métodos que acolhessem as dimensões qualitativas e quantitativas, como já havia apontado Piovesan.

Vejamos, por exemplo, o caso de Spinola e Costa (1972), da Universidade Federal da Bahia, que analisou os principais aspectos da brucelose e concluiu que avanços no tratamento ao agravo só poderiam ser conseguidos à medida que se conhecesse socialmente a população estudada, requisitando novas e mais adequadas abordagens à compreensão das dimensões comunitária e social em detrimento das essencialmente quantitativas. Ao mesmo tempo que os oponentes eram reciprocamente identificados, reclamava-se por pesquisas em torno de processos saúde-doença com um tratamento "oxigenante" em relação à denominada saúde pública tradicional ou clássica. $\mathrm{O}$ "oxigênio intelectual" provinha de uma modalidade de apropriação do ideário materialista-histórico, alguns com forte apoio em Lenin. Mas foi assim que saúde e doença passaram a ser pensadas em uma perspectiva relacional e processual, como desdobramentos histórico-estruturais. Os escritos inaugurais dessa abordagem refletem a conjuntura do momento e apresentam as ferramentas intelectuais necessárias à compreensão e análise sobre a prática médica e as relações saúde/sociedade. Citamos como exemplo as contribuições das teses de Donnangelo (1975), Arouca (1975) e Gonçalves (1979).

Nesse mesmo período, a fundação do Centro Brasileiro de Estudos da Saúde (Cebes), associação voltada para o debate e difusão do chamado Partido Sanitário e formada por um grupo de militantes no campo da saúde pública, reforçou o "movimento" com a formulação de políticas de saúde num contexto latino-americano - como referência ao Centro Panamericano de Planificação em Saúde. Em sua dimensão política, esse órgão foi decisivo para a reconhecida intelligentzia do campo, mobilizada politicamente em torno da fundamentação e operacionalização do direito geral à saúde e da redefinição do papel do Estado em todos os níveis de atenção à saúde.

A partir de 1973 emerge profusa publicação de artigos trazendo novas tendências e originalidades. Trabalhos com motivações interdisciplinares mais verticalizadas que os anteriores surgem na produção inédita de Haddad e Nogueira (1973), do Departamento de Medicina Social da USP de Ribeirão Preto, e de Ramos et al. (1973), do Departamento de Medicina Preventiva, Social e Saúde Pública da Faculdade de Ciências Médicas e Biológicas de Botucatu. São também de 1974 as primeiras publicações da Universidade de Campinas e da USP de São Carlos.

Com a consolidação de artigos que consideravam diferentes áreas de saber, os trabalhos começaram a mostrar maior número de colaboradores, multiprofissionais e interinstitucionais. 
Ao longo desse período não constatamos publicações temáticas, ainda que a área de nutrição tenha sido recorrente e bastante presente nas edições. Acompanhada de forte instrumentação estatística e escassas referências às ciências sociais, teve como base os diversos inquéritos alimentares para levantamento de estados nutricionais que acabariam por consubstanciar políticas que viriam a ser implantadas em décadas posteriores. Destacamos que o movimento dessa área (apresentado no exemplo de carta conceitual do Quadro 1) foi captado a partir da ênfase dada ao assunto, presente praticamente em quase todas as edições da RSP, revelandose em série, em que o conceito de nutrição sempre surgia acompanhado de instrumentação analítica da estatística/matemática. Não raro, os artigos traziam questões ligadas à desnutrição infantil, agravo de alta prevalência na saúde da época analisada. Logo, novos trabalhos surgiriam enfocando a mortalidade infantil relacionada à desnutrição, às doenças infectoparasitárias e às precárias condições sanitárias - associações essas que seriam cotejadas pelos posteriores estudos de risco.

Em 1974 registramos o primeiro suplemento, na esteira da necessidade do aumento de espaço editorial frente ao abrupto crescimento da produção científica nacional e do aumento de artigos para publicação, conforme apontamentos do próprio editor em diversas comunicações. Na mesma época, surgiram dois novos temas: o primeiro, na área de psiquiatria e psicologia com Simon (1974), que tratava da associação entre alcoolismo e saúde mental com referências ao modelo de Leavell e Clark, e o segundo, que trabalhava o tema do estresse num artigo de Gotlieb (1974) com referências ao caráter social do agravo.

Ecoando como proliferação dos departamentos acadêmicos criados desde a década anterior, a notação "medicina social" começava a se destacar a partir de 1975-1976. Notamos uma concomitante diminuição e rarefação dos trabalhos tipificados como CSHS, passando de 30\% para 25\% do total de artigos publicados, possivelmente em decorrência da incorporação, ao menos discursiva, de estudos interdisciplinares ou, pelo contrário, pelo fortalecimento de outra vertente epidemiológica como prenúncio e conformação do movimento da saúde coletiva em curso.

Ruffino-Netto (1977) atualizou, do nosso ponto de vista, com esforçado rigor matemático, certos padrões de delineamentos epidemiológicos no artigo "Modelos epidemiométricos em tuberculose: definição de "estados' e risco de infecção". Esse rigor ressurgiu no final da década, com a proposta de introdução de um modelo "epidemiométrico" com apurado desenvolvimento matemático na descrição do "risco de infecção" por equações diferenciais.

Gostaríamos, neste momento, de indagar a respeito da profusão de temas e problemas propostos pelos trabalhos: terá sido esse um advento que o "futuro" campo da saúde coletiva prenunciava? Compete-nos observar que os eventos alinhados com a nova conjuntura da saúde pública foram se delineando de maneira insidiosa. A "construção" de um pensamento em curso arregimentaria uma série de novas competências necessárias à absorção dos conhecimentos que a área (e o campo) colocava como demanda. A formação sanitária já instalada desempenharia papel fundamental como precursora de um alicerce estratégico. Colaboradores como Walter Leser influenciaram de maneira incisiva os desdobramentos que puderam ser observados na qualificação profissional e produção científica da saúde pública brasileira. Suas iniciativas remontam a um programa pioneiro desenvolvido no Departamento 
e Instituto de Medicina Preventiva da Escola Paulista de Medicina iniciado em 1956 e de sua atuação na Faculdade, além do cargo de secretário estadual de Saúde exercido posteriormente.

O objetivo original daquela iniciativa curricular foi educar futuros profissionais da saúde (inicialmente dirigido somente aos médicos) não só para os problemas de medicina curativa como para os da medicina preventiva. O ensino médico era realizado junto ao paciente e no seu domicílio, de forma que os estudantes entravam precocemente em contato com os vários problemas médicos-sanitários que afetavam o homem, a família e a comunidade que iriam futuramente servir (Bomfim, 2009). Alguns desdobramentos dessas iniciativas redundaram na reformulação dos vestibulares para medicina com a criação do Centro de Seleção de Candidatos das Escolas Médicas e na própria consolidação da Fundação Carlos Chagas. Mas foi a partir de 1967 que as ações puderam ser mais bem apreciadas no contexto em que tratamos essa cartografia. Na época Walter Leser assumia a Secretaria de Saúde do estado de São Paulo, em que implantou uma reforma administrativa, estabeleceu critérios para o preenchimento de cargos de chefia e criou a carreira de sanitarista, graças à cooperação formativa possível de estabelecimentos de ensino superior, especialmente a Faculdade de Saúde Pública da USP.

No âmbito da RSP, Sá (1976), com subsídios teóricos de Walter Leser, mostrou modelos para constituição de uma equipe local de saúde em unidade sanitária polivalente, num esforço de encurtar fronteiras materiais (para a população) e intelectuais (para os pesquisadores) no encontro entre EPI, CSHS e PPG. Ao se debruçar sobre problemas e desafios para o estágio integrado na Faculdade de Saúde Pública como preparo para o trabalho multiprofissional, Pereira e Harris (1976) também mostraram a premência de interlocução entre disciplinas nas unidades curriculares.

\section{Considerações finais}

Nossa pressuposição inicial acerca do perfil da RSP esteve associada à almejada divulgação, para cujo alcance sua internacionalização deveria ser uma meta ao menos esboçada. De fato, esse movimento foi explicitamente formulado em editorial assinado por Andrade (1978) ao focalizar a interdependência entre os avanços, as conquistas, os desafios e a adequação das normas de publicação a novos patamares. Já naquele momento a RSP propunha qualificar ainda mais as indexações com o intuito de superar a rigidez encontrada internacionalmente para a difusão dos artigos em nível mundial.

Toda cartografia se amparou em uma sociologia que - sob a perspectiva dos conteúdos editoriais, dos temas aceitos para publicação e de suas contextualizações espaçotemporais - proporcionou identificar uma intelligentsia que, ao corrigir os rumos da RSP, construía um perfil institucional ao mesmo tempo que possibilitava conhecer o conjunto de sua obra. Mas essa aproximação e descoberta só poderiam ocorrer com o auxílio-guia de uma ferramenta ou "tecnologia social" congruente e adequada aos nossos objetivos. Conforme as finalidades apontadas por Mannheim (1968, p.28), a sociologia do conhecimento pode servir como tratamento teórico compatível com a análise sistemática de uma organização institucional, sendo útil para o estudo de "escolas, universidades, academias, sociedades culturais, museus, bibliotecas, institutos de pesquisa, laboratórios, fundações e editoras". 
A dinâmica dessa abordagem buscou fundamentalmente duas situações explícitas: em primeiro lugar, "compreender o pensamento no contexto concreto de uma situação históricosocial, de onde só muito gradativamente emerge o pensamento individualmente diferenciado"; e, em segundo lugar, "associar os modos de pensamento concretamente existentes ao contexto de ação coletiva por meio do qual, em um sentido intelectual, [descobre-se] inicialmente o mundo" (Mannheim, 1968, p.31).

Assim pudemos perceber, por exemplo, a existência de uma tensão que expunha, de um lado, um padrão conservador representado pelas perspectivas tradicionais da editoria, e, de outro, um padrão de mudança frente às transformações representadas pela contínua exigência de modernização e adequação das publicações aos públicos nacional e internacional. Identificamos, portanto, uma forma de tradição higienista da saúde pública coexistindo com as reformistas proposições e saberes em curso. Essa interpretação indicaria que alguma resistência às "novas tendências" apresentadas no/pelo campo da saúde pública se configurasse como um contraconceito em relação ao insinuante movimento da saúde no final da década de 1970.

Para melhor traduzirmos o conjunto de interpenetrações, colisões, abalroamentos e raspões, foi fundamental o acompanhamento e a coordenação da carta conceitual (Quadro 2) para identificarmos o que emergia e o que submergia. Foram necessários aproximações e distanciamentos sistemáticos: as primeiras para focar, imergir e desvendar temas singulares - fossem eles inaugurais ou diferentes do perfil mais geral; os segundos, ao contrário, para desfocar e, assim, revelar temas seriados.

Aliada ao conjunto teórico apresentado, a investigação baseada na leitura do material permitiu delimitar um aspecto relevante e revelador, por seu caráter insurgente: o contexto interdisciplinar que insidiosamente foi sendo tecido ao longo das publicações, como a justificar um cenário de trânsitos e fronteiras entre áreas do saber. As possíveis "miscibilidades" observadas e descritas ao longo do texto entre as subáreas EPI, CSHS, PPG e CC ajudaram a reforçar essa afirmação, não perdendo de vista a predominância de uma epidemiologia em certo "estado de tormenta". Tudo indicou estar em jogo o estímulo ao contato entre áreas, justificado pelo crescente número de autores, não raro, originários de diferentes cadeiras e instituições. De maneira que, em vez de observarmos um aumento do número de artigos em CSHS ou PPG isoladamente, pudemos enxergar nas referências bibliográficas um movimento de interpenetração de conteúdos que denunciavam uma gradual apropriação por outras disciplinas e/ou áreas.

A exploração do mapeamento construído mostrou a existência de abordagens conflitantes não só entre as áreas como em seus interiores. A epidemiologia, por exemplo, de início amparada por estudos de bases naturais e bacteriológicas, logo se deparou com transformações advindas das próprias mudanças do perfil epidemiológico em movimento. Daí pensarmos uma "epidemiologia na tormenta" ao incorporar necessidades interdisciplinares para dar conta da construção do projeto de uma "nova" saúde.

O conceito inaugural de risco - evento singular - foi um dos pilares que sustentaria novas proposições para a área, fortalecido e fortalecendo o poder métrico das análises matemáticas e estatísticas, aperfeiçoadas pelo nascente processo de informatização. Arriscamos afirmar que aí estavam sendo gestadas as circunstâncias propícias para o desenvolvimento de um 
pensamento epidemiométrico de avaliação, que talvez não tivesse sido possível em outro momento sem a ideia de cálculo de chances de adoecimento ou de morte.

Lentamente, e em conjunto com novas apropriações epistemológicas, os padrões do conhecimento em transformação transcenderam as bases predominantemente biológicas, e isso também contribuiu para a formação e a identificação do perfil da RSP. Ao relacionar essas proposições, encontraremos, então, "epidemiologias" a se conversar e a se desentender em contínua tensão. Uma "compostagem" teria sido requerida para administrar as publicações, tornando-as mais atrativas para uma parcela maior de leitores.

Nesse percurso em busca de um perfil, fomos conduzidos a reconhecer a congruência entre discurso editorial e publicações da RSP, tal a fidelidade de propósitos demonstrada desde o Laboratório de Higiene e de Oswaldo Paulo Forattini à frente dessa missão como um de seus mais influentes colaboradores. A força desse compromisso, em diversos momentos, é ilustrada pelo fato de a editoria ser confundida com o próprio editor, constituindo uma propriedade particular que costumamos citar como perfil editorial, nesse caso materializado na missão de estimular e disseminar conteúdos de qualidade na área de saúde pública, como propulsora de desenvolvimento nas pesquisas e nas formações profissionais.

A abertura às publicações interinstitucionais e a diversidade abrangente de temas representaram esse alargamento a que nos referimos no transcorrer das publicações e que acabou por tipificar o periódico, dado o intenso movimento temático verificado nos últimos anos cartografados.

\section{AGRADECIMENTO}

O autor agradece à Coordenação de Aperfeiçoamento de Pessoal de Nível Superior a concessão de bolsa de doutorado.

\section{NOTAS}

* O artigo é decorrente da pesquisa que resultou na tese de doutorado Diálogos de fronteira: uma cartografia de revistas do campo da saúde coletiva, defendida por Maurici Tadeu Ferreira dos Santos na Escola Paulista de Medicina/Universidade Federal de São Paulo em 2014, sob orientação de Mara Helena de Andréa Gomes e coorientação de Cássio Silveira.

${ }^{1}$ Atual Coordenação de Aperfeiçoamento de Pessoal de Nível Superior (Capes), criada em 11 de julho de 1951 pelo decreto 29.741 .

\section{REFERÊNCIAS}

ALVARENGA, Augusta; CIARI JÚNIOR, Cyro; SANTOS, Jair.

Índice de status sócio-econômico da família da mulher grávida que freqüenta o Centro de Saúde Geraldo de Paula Souza da Faculdade de Saúde Pública da Universidade de São Paulo. Revista de Saúde Pública, v.7, n.4, p.351-367. 1973.

ANDRADE, Maria Teresinha.

Editorial: A Revista de Saúde Pública na literatura mundial. Revista de Saúde Pública, v.12, n.3, p.259-266. 1978.
ARANTES, Gilberto; RUFFINO-NETTO, Antonio. Tendência da subnotificação de casos no decorrer da epidemia de meningite meningocócica ocorrida no Estado de São Paulo, Brasil, no período de 1971/75. Revista de Saúde Pública, v.11, n.2, p.182-187. 1977.

AROUCA, Sérgio.

O dilema preventivista: contribuição para a compreensão e crítica da medicina preventiva. Tese (Doutorado em Medicina Social) - Faculdade de Ciências Médicas, Universidade Estadual de Campinas, Campinas. 1975. 
BAKST, Henry J.

Community health and departments of preventive medicine. Archives of Environmental Health, v.15, n.1, p.102-106. 1967.

BARBOSA, Victorio.

Estudo descritivo do suicídio no município de São Paulo (Brasil), 1959 a 1968. Revista de Saúde Pública, v.8, n.1, p.1-14. 1974.

BARROS, Aluísio.

Produção científica em saúde coletiva: perfil dos periódicos e avaliação pela Capes. Revista de Saúde Pública, v.40, número especial, p.43-49. ago. 2006.

BOMFIM, José Ruben de Alcântara.

Walter Sidney Pereira Leser: das análises clínicas à medicina preventiva e à saúde pública. São Paulo: Hucitec. 2009.

BRUNET, Roger.

Le dechiffrement du monde. Paris: Belin. 2001.

CANESQUI, Ana Maria (Org.).

Ciências sociais e saúde. São Paulo: Hucitec;

Abrasco. 1997.

CARVALHO, Leandro et al.

Produção e citação em saúde coletiva: um olhar a partir dos periódicos Cadernos de Saúde Pública e Revista de Saúde Pública. Cadernos de Saúde Pública, v.23, n.12, p.3023-3030. 2007.

CATRIB, Paula Regina; OLIVEIRA, Isabel Cristina. A cartografia na enfermagem: uma proposta de abordagem metodológica. Escola Anna Nery Revista de Enfermagem, v.14, n.2, p.399-405. 2010.

CIARI JÚNIOR, Cyro; ALMEIDA, Pedro. Elementos de avaliação do "risco gravídico". Revista de Saúde Pública, v.6, n.1, p.57-78. 1972.

CUETO, Marcos.

O valor da saúde: história da Organização Panamericana de Saúde. Rio de Janeiro: Editora Fiocruz. 2007.

DONNANGELO, Maria Cecilia Ferro.

Medicina e sociedade: o médico e seu trabalho. São Paulo: Pioneira de Ciências Sociais. 1975.

GOMES, Mara Helena.

Apontamentos socioantropológicos sobre comunidade e Saúde. Revista de Saúde Pública, v.40, n.3, p.528-536. 2006.

GOMES, Mara Helena; GOLDENBERG, Paulete. Interfaces e interlocuções: os congressos de ciências sociais em saúde. Revista Ciência e Saúde Coletiva, v.18, n.1, p.251-264. 2003.

GONCCALVES, Ricardo Bruno.

Medicina e história: raízes sociais do trabalho médico. Dissertação (Mestrado em Medicina) - Faculdade de Medicina, Universidade de São Paulo, São Paulo. 1979.
GOTLIEB, Sabina.

Alguns aspectos da mortalidade entre japoneses e seus descendentes residentes no município de São Paulo, Brasil. Revista de Saúde Pública, v.8, n.4, p.411-420. 1974.

GUIMARÃES, Raul; RIBEIRO, Helena.

O tratamento cartográfico da informação em saúde do trabalhador. Revista Brasileira de Epidemiologia, v.13, n.4, p.577-586. 2010.

HADDAD, Nagib; NOGUEIRA, Jarbas Leite. O envolvimento da comunidade rural de Cássia dos Coqueiros (São Paulo, Brasil) em programas de saúde. Revista de Saúde Pública, v.7, n.2, p.115-122. 1973.

IVERSSON, Lygia. Aspectos epidemiológicos da meningite meningocócica no município de São Paulo (Brasil), no período de 1968 a 1974. Revista de Saúde Pública, v.10, n.1, p.1-16. 1976.

JOLY, Fernand. A cartografia. Campinas: Papirus. 1990.

KRAUSS, Rosa.

Algumas reflexões sobre a formação de recursos humanos para a saúde pública. Revista de Saúde Pública, v.11, n.1, p.151-155. 1977.

LIBAUT, André.

Geocartografia. São Paulo: Companhia Editora Nacional. 1975.

LIMA-GONÇALVES, Ernesto et al.

Plano de reformulação da assistência ambulatorial do Instituto Nacional de Previdência Social na cidade de São Paulo. Revista de Saúde Pública, v.6, n.2, p.135-146. 1972.

LUCCHESI, Bruna et al.

Educação sanitária e medicina preventiva. Revista de Saúde Pública, v.3, n.1, p.83-91.1969.

MANNHEIM, Karl.

Ideologia e utopia. Rio de Janeiro: Zahar. 1968.

MELLO, Guilherme Arantes.

Revisão do pensamento sanitário como foco no centro de saúde. Tese (Doutorado em Medicina Preventiva) - Faculdade de Medicina, Universidade de São Paulo, São Paulo. 2010.

NUNES, Everardo.

As ciências sociais em saúde: reflexões sobre as origens e a construção de um campo de conhecimento. Revista Saúde e Sociedade, v.1, n.1, p.5-21. 1992.

PEREIRA, Isabel; HARRIS, William Moffitt. Estágio integrado na Faculdade de Saúde Pública da Universidade de São Paulo: preparo para o trabalho multiprofissional. Revista de Saúde Pública, v.10, n.3, p.257-266. 1976. 
PIOVESAN, Armando.

Medicina privada e saúde pública estariam convergindo? O problema e argumentos que justificariam o preparo do estudante de medicina em medicina comunitária. Revista de Saúde Pública, v.1, n.2, p.193-200. 1967a.

PIOVESAN, Armando.

O desenvolvimento das ciências da conduta aplicadas à saúde, na América Latina. Revista de Saúde Pública, v.1, n.1, p.97-98. 1967b.

RAMOS, Maria Iraci et al.

Análise de dados socioeconômicos e sanitários de famílias residentes no distrito-sede de Botucatu (São Paulo, Brasil), em 1969. Revista de Saúde Pública, v.7, n.2, p.161-179. 1973.

RAMOS, Reinaldo.

O treinamento de planejadores do setor saúde. Revista de Saúde Pública, v.2, n.2, p.207-215. 1968.

\section{RUFFINO-NETTO, Antonio.}

Modelos epidemiométricos em tuberculose: definição de "estados" e risco de infecção. Revista de Saúde Pública, v.11, n.2, p.188-198. 1977.

SÁ, Evelin.

Equipe local de saúde: sugestões para a abrangência de sua caracterização. Revista de Saúde Pública, v.10, n.1, p.75-102. 1976.
SILVEIRA, Maria Helena.

Considerações sobre o sistema de informação no setor saúde. Revista de Saúde Pública, v.8, n.1, p.119-128. 1974.

SILVEIRA, Maria; GOTLIEB, Sabina. Acidentes, envenenamentos e violências como causa de morte dos residentes no município de São Paulo, Brasil. Revista de Saúde Pública, v.10, n.1, p.45-55. 1976.

SIMON, Ryad.

Prevenção primária do alcoolismo: esboço de programa para população urbana brasileira. Revista de Saúde Pública, v.8, n.3, p.249-255. 1974.

SOUZA, José Maria.

Recursos humanos em saúde pública. Revista de Saúde Pública, v.10, n.3, p.253-256. 1976.

SOUZA, Raphael de Paula.

Editorial. Revista de Saúde Pública, v.1, n.1, p.1-2. 1967.

SPINOLA, Ademário; COSTA, Moacyr.

Brucelose humana em operários de um frigorífico no município de Salvador, Bahia, Brasil. Revista de Saúde Pública, v.6, n.2, p.157-165. 1972.

WINSLOW, Charles-Edward.

The untilled fields of public health. Science, v.51, n.1306, p.23-33. 1920. 